\title{
Ю.С. Осаченко
}

\section{ОБРАЗОВАТЕЛЬНАЯ ПРАКТИКА КАК ЗАБОТА О СЕБЕ: ОТ КОНЦЕПТА К МИФУ}

\begin{abstract}
Рассматриваются некоторые аспекты формирования перформативной идентичности участников образовательного процесса (учащегося и учащего) как практики заботы о себе. В перформативных теориях понятие идентичности связывается с действиями субъекта, которые способствуют производству нового порядка (телесного, психического, сочиального, этического, экзистенциального) и определяют принадлежность к нему. Практика заботы о себе рассматривается в динамике - от кониепта к мифу как синкретическому единству различных измерений заботы.

Ключевые слова: забота о себе, образование, миф, идентичность.
\end{abstract}

«Легко ли познать самого себя (ведь не первый же встречный начертал это на Пифийском храме!)? Или, наоборот, это трудно и доступно не всякому? ...Познав самих себя, мы одновременно познаем заботу, в которой нуждаемся, а без такого познания мы никогда этого не поймем... каким образом могли бы мы отыскать са́мое „само“» [1. С. 256].

Забота о себе, как онтологическая трансформация идентичности того «самого Само», о котором говорится у Платона, как практика перформативного преобразования самого себя, безусловно, связана с глубинной интенцией образования. Образование понимается здесь онтологически как перманентный поиск и обретение образа себя. Но образ этот не статичен и не может быть «отмерен или взвешен» в качестве некоторого само-тождественного сущего. Этот образ - имманентно мифичен, поскольку аффективно переживаем, ценностно-практически насущен и одновременно - достраиваем в качестве горизонта жизненного мира, в контекст которого помещает себя субъект как в «контекст своей ситуации». Этот образ индивидуален в той же мере, в какой он дивидуален, т.е. разделяем с сообществом, встраиваем в контекст коллективного со-действия и событийности.

Образование и само-образование как забота, как экзистенциальная динамика имеют в таком контексте мифологическое измерение. Это измерение можно обозначить как потенциал возможного трансформирования и синтетического соединения различных аспектов целого: индивидуального и дивидуального, когнитивного и ценностного, образного и понятийного. В перформативных теориях понятие идентичности связывается с теми действиями субъекта, которые способствуют производству нового порядка (телесного, психического, социального, этического, экзистенциального) и определяют принадлежность к нему. И такой ракурс рассмотрения актуален и злободневен, поскольку динамика современного мира требует не столько поверхностного усвоения и/или изменения ролей (социальных, профессиональных, деятельностных), сколько сущностной пластичности бытия как со-бытия и субъекта как дивидуального путешественника, переступающего границы известного. 
Забота о себе в контексте подлинно актуальной образовательной практики, предполагает принцип взаимной открытости, интерактивности и согласования горизонтов заботы учителя и ученика. Учитель заботится о том, чтобы ученик не догматически воспринимал некоторые алгоритмы или «знанияумения-навыки», не просто воспроизводил некоторый набор правил, синтаксис, не просто миметически усваивал некие сложившиеся идеи, нормы, стереотипы, но постигал семантику, смысл как событие, опыт как экзистенциальное приключение в некотором горизонте совместности, в различных режимах вовлеченности.

Как писал М. Фуко, «забота о себе - это что-то такое, что, как вы сами в том убедитесь, обязательно должно быть опосредовано кем-то другим, учителем. Невозможно заботиться о себе без посредства учителя, без учителя нет заботы о себе. Но от чего зависит позиция учителя и о чем он заботится прежде всего, так это о том, как сможет заботиться о себе его подопечный. В отличие от врача или главы семьи он не заботится о теле, не заботится об имуществе. В отличие от учителя в школе он не заботится о том, чтобы развить умения и способности обучаемого, не стремится научить его красиво говорить, не учит побеждать соперника и т. д. Учитель - это тот, кто заботится о том, как заботится о себе его ученик, и для кого любовь к своему ученику - это способ позаботиться о его заботе о самом себе» [2. С. 75].

Перформативная идентичность как перманентно осуществляемая трансформация синкретической целостности «образа-себя», того «самого само», о котором шла речь ранее, текучая и парадоксальная себе (не-)тождественность не может складываться иначе, чем в контексте взаимодействия взаимной заботы: docendo discimus - уча, мы сами учимся, образовываясь сами, мы образуем(-ся) Другим. Образовательная практика такого типа предполагает открытость Другому, децентрацию, интерактивность и «рискованное мышление» в качестве своих принципов.

Традиционная образовательная практика со времен средневекового, а затем и классического университета протекала преимущественно в структуре закрытой рациональности. Закрытая, или формальная, рациональность исходит из пред-заданности движения в некоторой концептуальной (нормативной, ценностно-смысловой) схеме, протекает в закрытом смысловом пространстве, очерчиваемом содержанием исходных утверждений, не подлежащих критическому анализу.

Новая неклассическая модель образовательных практик, открытая рациональность и «рискованное мышление» предполагают способность выхода за пределы статичной концептуальной схемы, за рамки жестких конструкций. Открытая рациональность может быть определена словами Г. Башляра: «Рационально мы организуем лишь то, что реорганизуем... Реорганизация - это подчистка, некая разновидность более тонкого освоения, но одновременно это и пробы: рационализм непременно открыт» [3. С. 288-289]. Реорганизация предполагает системную работу по выявлению имплицитных допущений, лежащих в основании любой парадигмы (критическое мышление), перманентную рефлексию оснований нашей деятельности, границ действия и типов взаимодействия. Однако само по себе рациональное действие и концептуализация протекают в некотором до-рефлексивном, синкретичном горизонте жизненного мира и «своей ситуации», которые перманентно мифич- 
ны. Забота о себе - это в том числе заботливое внимание к этим контекстам, позволяющее избегать превращения практики образования в практику муштры и выучки.

Данные контексты мы можем прояснить, обращаясь к теории коммуникативного действия Юргена Хабермаса, а также к модели «открытого образования» как «рискованного мышления» Ганса Ульриха Гумбрехта.

«Жизненный мир» как нетематизированный горизонт значений составляет основание жизненного опыта индивида. Внешние воздействия соотносятся с этим основанием, противопоставляются ему, сравниваются по отношению к нему. Этот горизонт значений состоит из предшествующего индивидуальному опыту сознающего запаса (различенных ранее и сохраненных в коллективной памяти) смыслов и ценностей, сосредоточенного в культуре.

Важнейшим моментом является здесь идея интеракции, интерсубъективности, т.е. познавательных, нравственно-практических, социально-исторических аспектов человеческого взаимодействия. Хабермас исследует типы действия в связи с соответствующими им типами рациональности, подразумевающей идею активности и суверенности действующих субъектов - личностей. При изучении действия с точки зрения отношения действующего человека к миру имеются в виду четыре аспекта: действие телеологическое (стратегическое), норморегулирующее, экспрессивное (драматургическое) и коммуникативное (нацеленное на понимание). Ни один из аспектов и элементов действия сам по себе не дает определения человеческого.

Рационализированный «жизненный мир» использует языковые структуры, определяющие различение и установление границ между объективным, социальным и субъективным мирами. Люди относят себя одновременно ко всем трем мирам. Поэтому каждое действие обладает комплексным характером: действие есть система отношений, состоящая из объективных фактов, личностного опыта и социальных норм (смыслы, ценности, нормы). Действие управляется знанием, но это знание может быть различным. Научное знание не является ни единственно возможным, ни единственно рациональным. Опыт участников социального взаимодействия состоит из практического «знания-как», а не только из научного знания. Дифференцированные структуры «жизненного мира» изначально направлены, по мнению Ю. Хабермаса, на производство и воспроизводство культуры (знания), общества (легитимного порядка) и личности (индивидуальной идентичности). Однако горизонт «жизненного мира» как мифологический окоем не дифференцируем до конца и несводим к отчетливости кванитфицированных элементов. «Для коллективного сознания крайне необходима живительная сила ритуального возвращения к истокам, которая гарантирует, как это показал Дюркгейм, социальную солидарность; но в равной мере необходима и явная видимость свойства возвращения к истокам, от которых должен бежать член социального коллектива, вырастающего из родства общины, формируясь в Я. Таким образом, силы и власть корней, истоков пытаются перехитрить и обожествить практически в одно и то же время. В древней истории субъективности эти силы представляют собой первую ступень просвещения» [4. С. 60].

В нем всегда присутствует скрытая динамика различений, охватить которую в системе знания невозможно - лишь в рамках сопереживаемого опыта, избегающего любой отчетливой концептуализации. И тем не менее до- 
ступных пониманию в свете взаимной заботы участников герменевтического процесса. И здесь в контексте образования становится понятной важнейшая роль гуманитарных наук.

Ганс Ульрих Гумбрехт разработал концепцию гуманитарных наук как «рискованного мышления» и ее влияния на университеты будущего, он говорил: «...я предпочитаю рассматривать Humanities and Arts (a с учетом современных обстоятельств - и некоторые «классические» естественно-научные дисциплины) как пространства, обеспечивающие возможность рискованного мышления» [5. S. 140-147].

Новое прочтение гуманитарных наук полагает их как активность сознания во всем многообразии опыта понимания, идущего навстречу воображению: аспект восприятия мира, который и обеспечивает многоцветность мысленных образов и интенсивность чувств в качестве функционального эквивалента четко определенных и абстрактных концепций, требуемых наукой. В то же время, по мысли философа, гуманитарные науки должны опираться на акты суждения, на способность проводить различия и принимать решения, которые не могут быть основаны на “объективных" измерениях или на дедуктивных логических выводах. Мысль и сознание - область действия, эксперимента, результаты которого невозможно заранее предугадать. Именно университет должен стать таким полем «рискованного и перспективного мышления», которое образует активный ум, порождает сообщества «человека осмысляющего», человека, обладающего не «ставшей», а перформативной идентичностью, заботливо созидающего и со-творящего новые смыслы, ценности, нормы.

\section{Лumepamypa}

1. Платон. Собрание сочинений : в 4 т. / под ред. А.Ф. Лосева и др. М. : Мысль, 1990. Т. 1. $860 \mathrm{c}$.

2. Фуко М. Герменевтика субъекта: Курс лекций, прочитанных в Коллеж де Франс в $1981-$ 1982 учебном году / пер. с фр. А.Г. Погоняйло. СПб. : Наука, 2007. 677 с.

3. Башляр Г. О природе рационализма // Новый рационализм. М., 1987. 376 с.

4. Хабермас Ю. Философский дискурс о модерне / пер. с нем. М. : Весь Мир, 2003. 416 с.

5. Gumbrecht H.U. Riskantes Denken // Der kritische Blick. Über intellektuelle Tätigkeiten udn Tugenden Uwe Justus Wenzel. Frankfurt am Main, 2002.

Yuliya S. Osachenko, Tomsk State University (Tomsk, Russian Federation).

E-mail: july11@list.ru

Vestnik Tomskogo gosudarstvennogo universiteta. Filosofiya. Sotsiologiya. Politologiya-Tomsk State University Journal of Philosophy, Sociology and Political Science. 2018. 42. pp. 154-158.

DOI: $10.17223 / 1998863 \mathrm{X} / 42 / 16$

EDUCATIONAL PRACTICE AS CARE OF THE SELF: FROM CONCEPT TO MYTH

Keywords: care of the self; education; myth; identity.

The article examines some aspects of the formation of the performative identity of the participants in the process of education (teacher and student) as a practice of care of the self. In performative theories the concept of identity is associated with the subject's actions which contribute to the production of new relation types (physical, mental, social, ethical, existential) and determine belonging to it. The practice of care of the self is considered in dynamics - from concept to myth as a syncretic unity of various dimensions of care. In the real modern educational practice, care of the self demands an approach of mutual openness, interactivity and conformity of borders of care between the teacher and the student. The teacher should care about the non-dogmatic perception of algorithms or "knowledgeskills-experience" by the student. The teacher should make sure the student understands semantics and sense as an event and experience, as an existential adventure rather than simply reproduces some syn- 
tax. Performative identity as a permanently continuing process of transformation of the "image of the self", as it was mentioned above, is like a fluid, paradoxical (non-)identity that should be created only in the context of mutual care: docendo discimus - we learn by teaching. This kind of educational practice demands openness to the Other, decentration, interactivity and "risky thinking" as its principles.

\section{References}

1. Plato. (1990) Sobraniye sochineniy: $v 4 t$. [Collected Works. In 4 vols]. Translated from Ancient Greek. Vol. 1. Moscow: Mysl'.

2. Foucault, M. (2007) Germenevtika sub"ekta: Kurs lektsiy, prochitannykh v Kollezh de Frans v 1981-1982 uchebnom godu [Hermeneutics of the Subject: A course of lectures delivered at the Collège de France in 1981-1982]. Translated from French by A.G. Pogonyaylo. St. Petersburg: Nauka.

3. Bashlar, G. (1987) Novyy ratsionalizm [New Rationalism]. Translated from French by Yu.Senokosov, M.Turover. Moscow: Progress.

4. Habermas, Ju. (2003) Filosofskiy diskurs o moderne [Philosophical Discourse on the Modern]. Translated from German. Moscow: Ves' Mir.

5. Gumbrecht, H.U. (2002) Riskantes Denken [Risky thinking]. In: Wenzel, U.Ju. (ed.) Der kritische Blick. Über intellektuelle Tätigkeiten udn Tugenden [The Critical View. About Intellectual Activities and Virtues]. Frankfurt am Main: Fischer Taschenbuch Verlag. 